\title{
Polymerisation and crosslinking of fibrin monomers in diabetes mellitus
}

\author{
A. Lütjens ${ }^{1}$, T.W. Jonkhoff-Slok ${ }^{1}$, C.Sandkuijl ${ }^{1}$, E.A.v.d. Veen ${ }^{2}$ and J.v.d. Meer ${ }^{2}$ \\ ${ }^{1}$ Department of Clinical Chemistry, Andreas Ziekenhuis, and \\ ${ }^{2}$ Department of Internal Medicine, Free University Hospital, Amsterdam, The Netherlands
}

\begin{abstract}
Summary. Polymerisation and crosslinking of fibrin monomers was studied in 35 healthy volunteers and in 42 poorly controlled diabetic patients. Polymerisation did not show any difference between control subjects $(n=10)$ and diabetic patients $(n=11)(p>0.1)$, although fibrinogen was $35 \%$ more glycated in the diabetic patients $(p<0.001)$. Alpha chain crosslinking in the diabetic patients, however, was impaired as is shown from an increase in intermediate alpha polymers with a concomitant decrease in alpha monomer disappearance. A significant positive correlation was found between the degree of glycation of fibrinogen and the defective alpha chain polymerisation $(r=0.86, p<0.005)$. These results were consistent with the results of thrombin and reptilase experiments. The reaction rate with reptilase did not show any dif-
\end{abstract}

ference between the two groups $(p>0.1)$, whereas the reaction rate with thrombin was significantly slower in the diabetic group compared to the control subjects $(p<0.001)$. Purified fibrin clots obtained from the diabetic patients were more susceptible to plasmin than clots obtained from control subjects. It is concluded that in poorly controlled diabetic patients polymerisation of fibrin monomers is normal, but crosslinking of the alpha chains is impaired, leading to a higher susceptibility of the clots to plasmin degradation.

Key words: Fibrinogen, polymerisation, crosslinking, glycation, diabetes mellitus, thrombin time, reptilase time, plasmin clot lysis.
Diabetes mellitus is associated with early and sometimes rapidly progressing micro- and macroangiopathic lesions. The accompanying anomalies of the haemostatic system may be either the cause or consequence of the vascular damage. As to fibrinogen, a key protein for the coagulation process, various disturbances have been described, such as: fibrin depositions in various tissues [1], altered fibrin(ogen) metabolism [2, 3], increased fibrin complexes in circulating blood $[4,5]$, reduced fibrinogen survival [6] and increased concentrations of fibrinogen in plasma [7]. Non-enzymatical glycation of proteins results from sustained hyperglycaemia [8]. Fibrinogen turned out to be no exception $[9,10]$. Glycation takes place at lysine molecules, which play an important role in the fibrinogen metabolism [11].

We, therefore, raised the question of whether the increased glycation of fibrinogen influences its function.

In this study the polymerisation, subsequent crosslinking of fibrin monomers and plasmin lysis of fibrin clots in control subjects and in poorly controlled diabetic patients are compared.

\section{Subjects and methods}

Four protocols were used to assess the influence of the increased glycation: protocol A: polymerisation of fibrin monomers; protocol B: crosslinking of fibrin polymers; $\mathrm{C}$ : reaction with thrombin and reptilase (venom of Batrops atrox); and protocol D: clot lysis by plas$\min$.

\section{Subjects}

Thirty-five healthy volunteers and 42 diabetic patients were included in the study. All patients were Type 1 (insulin-dependent) diabetic patients according to the WHO classification [12].

Table 1 states the characteristics of the subjects participating in the three protocols. Six control subjects participated in two protocols. No drugs influencing the clotting process were taken by any of the participants. Clotting factor XIII was normal in all patients.

\section{Methods}

Protocol A: Polymerisation of fibrin monomers. Blood was taken from an antecubital vein without stasis. Clotting was prevented by EDTA $0.19 \mathrm{~mol} / \mathrm{l}$. Benzamidine $10 \mathrm{mmol} / \mathrm{l}$ was added as serine protease inhibitor. 
Table 1. Characteristics of diabetic patients (D) and control subjects (C) participating in protocol A (polymerisation of fibrin monomers), protocol B (crosslinking of fibrin polymers), protocol C (thrombin and reptilase reaction) protocol D (clotlysis). (Mean, range)

\begin{tabular}{|c|c|c|c|c|c|c|c|}
\hline Protocol & Group & $n$ & $\begin{array}{l}\text { Age } \\
\text { (years) }\end{array}$ & $\begin{array}{l}\text { Diabetes dura- } \\
\text { tion (years) }\end{array}$ & $\begin{array}{l}\mathrm{HbA}_{1 \mathrm{c}} \\
(\%)\end{array}$ & $\begin{array}{l}\text { Fibrinogen } \\
(\mathrm{g} / \mathrm{l})\end{array}$ & $\begin{array}{l}\text { Glucose } \\
(\mathrm{mmol} / 1)\end{array}$ \\
\hline A & $\begin{array}{l}\mathrm{D} \\
\mathrm{C}\end{array}$ & $\begin{array}{l}11 \\
10\end{array}$ & $\begin{array}{c}58 \\
(36-68) \\
30 \\
(23-50)\end{array}$ & $\begin{array}{l}22 \\
(8-32) \\
- \\
-\end{array}$ & $\begin{array}{l}11.5 \\
(5.2-16.5) \\
4.3 \\
(3.8-4.7)\end{array}$ & $\begin{array}{c}4.0 \\
(3.1-5.5) \\
2.6 \\
(1.8-3.5)\end{array}$ & $\begin{array}{l}12.9 \\
(7.3-17.4) \\
5.0 \\
(4.1-5.4)\end{array}$ \\
\hline B & $\begin{array}{l}\mathrm{D} \\
\mathrm{C}\end{array}$ & $\begin{array}{r}8 \\
10\end{array}$ & $\begin{array}{c}59 \\
(16-85) \\
40 \\
(21-63)\end{array}$ & $\begin{array}{l}20 \\
(2-31) \\
- \\
-\end{array}$ & $\begin{array}{l}11.6 \\
(7.0-14.2) \\
3.8 \\
(3.1-4.6)\end{array}$ & $\begin{array}{l}4.1 \\
(2.7-6.1) \\
2.9 \\
(2.5-3.4)\end{array}$ & $\begin{array}{l}12.8 \\
(8.1-15.8) \\
4.8 \\
(4.0-5.1)\end{array}$ \\
\hline $\mathrm{C}$ & $\begin{array}{l}\mathrm{D} \\
\mathrm{C}\end{array}$ & $\begin{array}{l}16 \\
12\end{array}$ & $\begin{array}{l}60 \\
(22-80) \\
49 \\
(19-75)\end{array}$ & $\begin{array}{l}18 \\
(3-30) \\
- \\
-\end{array}$ & $\begin{array}{l}8.0 \\
(5.7-15.0) \\
4.0 \\
(3.0-4.8)\end{array}$ & $\begin{array}{l}3.0 \\
(2.2-3.9) \\
2.8 \\
(2.2-4.1)\end{array}$ & $\begin{array}{l}10.6 \\
(7.0-14.8) \\
4.7 \\
(3.9-5.1)\end{array}$ \\
\hline
\end{tabular}

Plasma was prepared by two centrifugation steps $(4000 \mathrm{~g}$ 10 min). Fibrin monomers were prepared according to Belitser [13]. To plasma $10 \mathrm{U} / \mathrm{ml}$ thrombin was added. After incubation for $30 \mathrm{~min}$ at $37^{\circ} \mathrm{C}$, the clot was collected and washed 3 times in phosphate buffered saline $(0.14 \mathrm{~mol} / 1 \mathrm{NaCl}$ in $0.1 \mathrm{~mol} / \mathrm{l}$ phosphate buffer $\mathrm{pH}$ 7.2). The clot then was solved in $0.02 \mathrm{~mol} / 1$ acetic acid (ionic strength 0.12 ).

To start polymerisation, a standard amount of the clear monomer solution was brought into twenty fold its volume of $0.06 \mathrm{~mol} / \mathrm{l}$ phosphate buffer, $\mathrm{pH}$ 6.8. Polymerisation was followed spectrophotometrically at $350 \mathrm{~nm}$. (Pye Unicam SP8-400 UV/VIS, Philips, Eindhoven, The Netherlands).

As a measure for the polymerisation rate, the maximal incrase in absorbance at $350 \mathrm{~nm} / \mathrm{min}\left(\Delta \mathrm{A}_{\max } / \mathrm{min},(350 \mathrm{~nm})\right)$ was calculated from the maximal tangent of the sigmoidal clotting curve [14].

Protocol B: Crosslinking of fibrin polymers. Blood was collected in 0.1 volume of $129 \mathrm{mmol} / 1$ trisodium citrate $/ 10 \mathrm{mmol} / 1$ benzamidine. Plasma was prepared by two centrifugation steps (4000 $\mathrm{g}$, $10 \mathrm{~min}$ ). Plasma was clotted by adding $1.2 \mathrm{U}$ thrombin $/ 5 \mu \mathrm{mol}$ $\mathrm{CaCl}_{2}$ per milligram of fibrinogen. After various times up to $24 \mathrm{~h}$, the clots were collected and extensively washed in $0.15 \mathrm{~mol} / 1 \mathrm{NaCl}$. The clots, then, were treated overnight with $8 \mathrm{~mol} / 1 \mathrm{urea} / 2 \%$ sodium dodecylsulfate (SDS) $/ 0.02 \%$ dithiotreitol in $0.1 \mathrm{TrisHCl} \mathrm{pH} 6.8$ at $37^{\circ} \mathrm{C}$ in order to reduce disulphide bridges and to obtain separate fibrin chains. After further dilution with $8 \mathrm{~mol} / 1$ urea $/ 0.1 \%$ sodium dodecylsulfate, $11 \mu \mathrm{l}$ of the solution, containing $15 \mu \mathrm{g}$ fibrin chains, was subjected to polyacrylamide gel (PAG) electrophoreses on a $5 \%$ gel [15].

Monomers were obtained by adding EDTA $0.020 \mathrm{mmol} / 1$ instead of $\mathrm{CaCl}_{2}$ to the clotting mixture. Coomassie brilliant blau, R250 (Merck, Darmstadt, FRG) was used as dye.

The bands were scanned by an Elvi densitometer (Marius Instruments, Utrecht, The Netherlands).

Protocol $C:$ Thrombin and reptilase reactions Citrate plasma was prepared from blood ( 0.1 volume of $129 \mathrm{mmol} / 1$ trisodium citrate and 0.9 vol of blood). Fibrinogen concentration was adjusted to $2.0 \mathrm{~g} / 1$ using $0.15 \mathrm{~mol} / 1 \mathrm{NaCl}$. The plasma then was further diluted $1: 1$ with Owrens Veronal buffer [16] pH 7.35.

To $2 \mathrm{ml}$ of the diluted plasma $1 \mathrm{ml}$ of thrombin $(2 \mathrm{U} / \mathrm{ml})$ was added at time 0 and the reaction was followed spectrophotometrically at $350 \mathrm{~nm}$. In the reptilase assay plasma $(2.0 \mathrm{~g} / 1$ fibrinogen) was diluted 1:3 with Owrens Veronal buffer $\mathrm{pH} 7.35$ and 0.5 reptil- ase (Reptilase R, Boehringer, Mannheim FRG) was added, after which the clotting was recorded. The reaction rate was expressed as maximum increase in absorbance at $350 \mathrm{~nm} / \mathrm{min}\left(\Delta \mathrm{A}_{\mathrm{max}} / \mathrm{min}\right.$, $(350 \mathrm{~nm})$ ), calculated from the maximal tangent of the absorbance curve.

Protocol D: Clotlysis by plasmin. Blood was collected in $129 \mathrm{mmol} / \mathrm{I}$ trisodium citrate $/ 10 \mathrm{mmol} / 1$ benzamidine. After two centrifugation steps $(4000 \mathrm{~g}, 10 \mathrm{~min}$ ) endogenous plasminogen was removed by lysine-sepharose affinity chromatography [17]. Fibrinogen was purified using two glycine precipitations, using $2.1 \mathrm{~mol} / 1$ glycine at $4^{\circ} \mathrm{C}$. The last precipitate was resuspended in sodium phosphate buffer $0.1 \mathrm{~mol} / 1, \mathrm{pH} 6.4 / 10 \mathrm{mmol} / 1$ bezamidine and dialysed against $0.3 \mathrm{~mol} / 1 \mathrm{NaCl} / 10 \mathrm{mmol} / \mathrm{l}$ benzamidine during $16 \mathrm{~h}$ and against $0.3 \mathrm{~mol} / 1 \mathrm{NaCl}$ during another $8 \mathrm{~h}$. To $3 \mathrm{mg} / \mathrm{ml}$ of purified fibrinogen $225 \mu \mathrm{l}$ phosphate buffered saline $(0.14 \mathrm{~mol} / 1 \mathrm{NaCl}$ in $0.1 \mathrm{~mol} / 1 \mathrm{phosphatebuffer} \mathrm{pH} 7.4), 37.5 \mu \mathrm{l}$ poolserum as factor XIII donor, $225 \mu \mathrm{l}{ }^{125} \mathrm{I}$-fibrinogen (specific activity $3.7 \mathrm{MBq} / \mathrm{mg}$ fibrinogen, Amersham, Amersham, Bucksh, UK), 1.2 CU plasminogen (KabiVitrum, Stockholm, Sweden) and $3.6 \mathrm{U}$ thrombin $/ 15 \mu \mathrm{mol}$ $\mathrm{CaCl}_{2}$ were added. After $20 \mathrm{~h}$, the clots were collected on a glass rod and extensively washed in $0.15 \mathrm{~mol} / 1 \mathrm{NaCl}$. The clots then were immersed in $1200 \mathrm{U}$ streptokinase (Streptase, Hoechst Behringwerke, Marburg/Lahn, FRG) in phosphate buffered saline $(0.14 \mathrm{~mol} / 1$ $\mathrm{NaCl}$ in $0.1 \mathrm{~mol} / 1$ phosphate buffer $\mathrm{pH} 7.4$ ). After $0.5,1,2,3$ and $4 \mathrm{~h}$, an aliquot of the supernatant was taken. Radioactivity was counted in a multiwell gamma counter (Nuclear Enterprises, Beenham, UK). Lysis was expressed as \% radioactivity in the supernatant after correction for spontaneous lysis.

\section{General methods}

$\mathrm{HbA}_{1 \mathrm{c}}$ was estimated by affinity chromatography (Pierce Chemical Company, Rockford, Ill, USA, Ref. value 3.6-6.8\%). Fibrinogen was estimated by the method of Strengers [18]. (Ref. value $2.0-4.0 \mathrm{~g} / 1$ ). Factor XIII was estimated either by a clotting method, using dilutions of deficient plasma (Ref. value $50-150 \%$ ), or by the clotting FXIII $^{\mathrm{a}}$ inhibition test (Hoechst Behringwerke AG, Marburg/Lahn, FRG, Ref. value $70-150 \%$ ). Glycation of fibrin(ogen) was estimated by a modification of the hydroxymethylfurfural method as described previously [10]. 


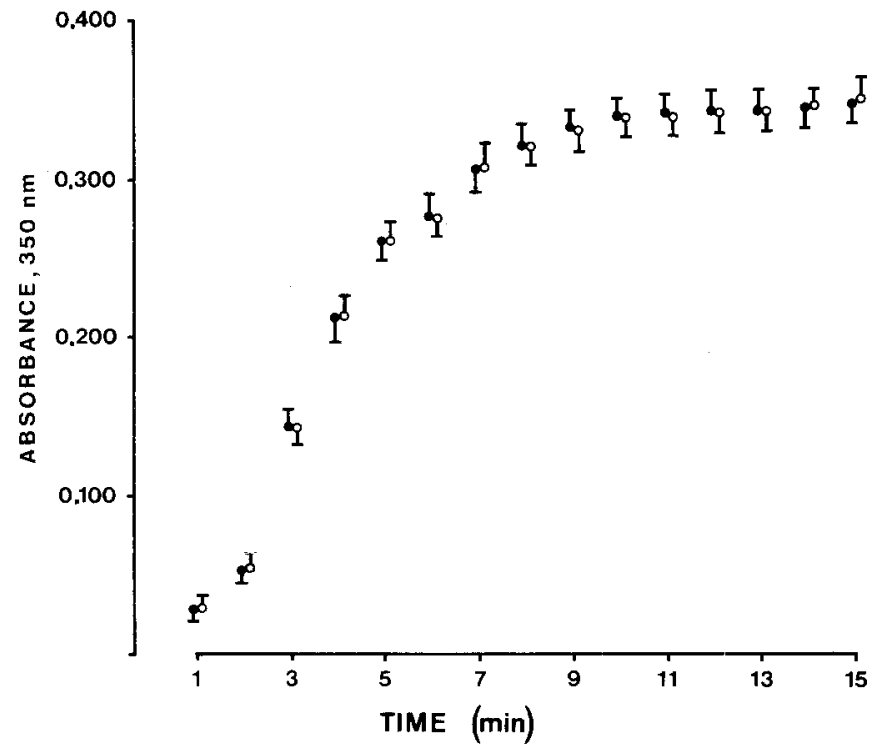

Fig. 1. Polymerisation curve of fibrin monomers. $100 \mu \mathrm{l}$ $(0.020 \mathrm{mg} / \mathrm{ml})$ monomer solution was brought into $2 \mathrm{ml}$ of $0.06 \mathrm{~mol} / 1$ phosphate buffer $\mathrm{pH} 6.8$. Absorbance at $350 \mathrm{~nm}$ was recorded (mean $\pm \mathrm{SD})$. $O$ diabetic patients; 0 control subjects

2 CONTROL SUBJECT

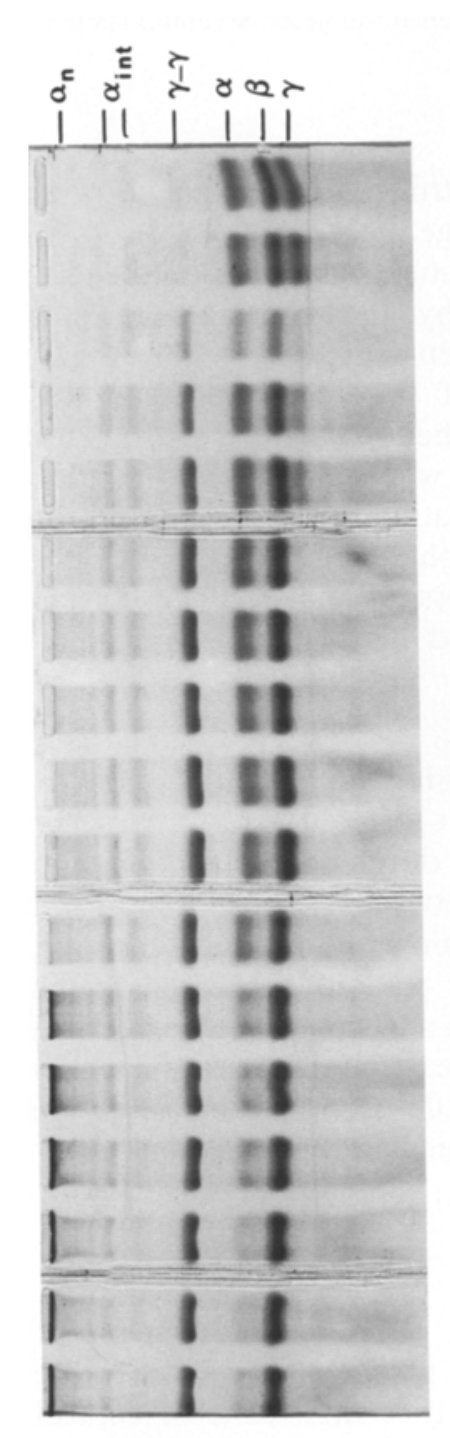

24

3

\section{Statistical analysis}

Results are expressed as mean \pm SEM or SD when indicated. For comparison of the two groups, Student's t-test for unpaired data was used. Correlation was assessed using the Kendall rank test [19] and orthogonal regression analysis as indicated.

\section{Results}

\section{Polymerisation}

The results of the polymerisation studies are shown in Figure 1. No difference in lagtime nor in increase in absorbance was found between the two groups. The degree of glycation of fibrinogen was significantly higher in the diabetic group $(1.30 \pm 0.08 \mathrm{~mol}$ glucose/mol fibrinogen) compared to the control subjects $(0.83 \pm 0.06 \mathrm{~mol}$ glucose $/ \mathrm{mol}$ fibrinogen $)$, whereas $\Delta \mathrm{A}_{\max } / \mathrm{min},(350 \mathrm{~nm})$ did not show any difference $(0.030 \pm 0.001$ in the diabetic group against $0.029 \pm 0.002$ in the control group.)
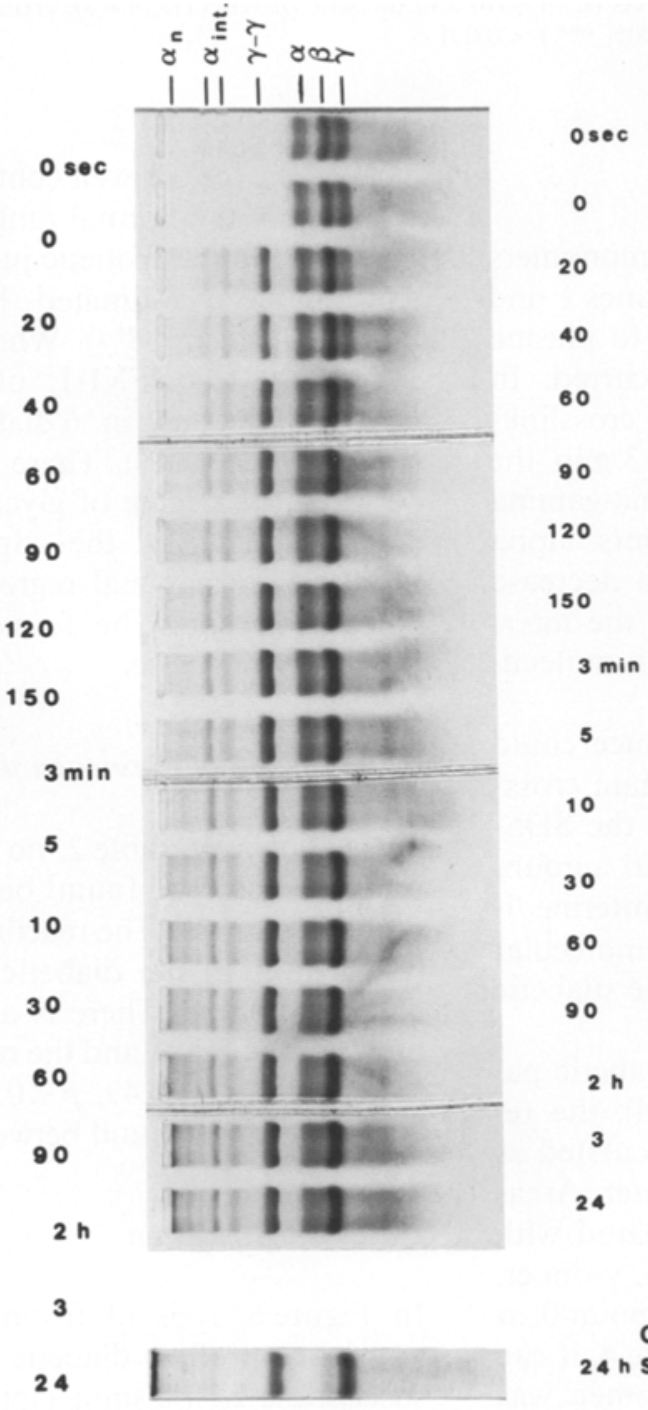

Fig. 2. SDS-PAG electrophoresis on a $5 \%$ gel of reduced fibrin monomers (lanes 1 and 2) and fibrin polymers (lanes 3-17) of a control subject. $\left(\alpha_{n}=\alpha_{n}\right.$ polymer; $\alpha_{\text {int }}=$ intermediate $\alpha$-polymers)

Fig.3. SDS-PAG electrophoresis on a

CONTROL $5 \%$ gel of reduced fibrin monomers $24 \mathrm{hSUBJECT}$ (lanes 1 and 2) and fibrin polymers (lanes 3-17) of a diabetic patient. Lane 18: $24 \mathrm{~h}$, control subject. $\left(\alpha_{n}=\alpha_{n}\right.$ polymer; $\alpha_{\text {int }}=$ intermediate $\alpha$-polymers) 


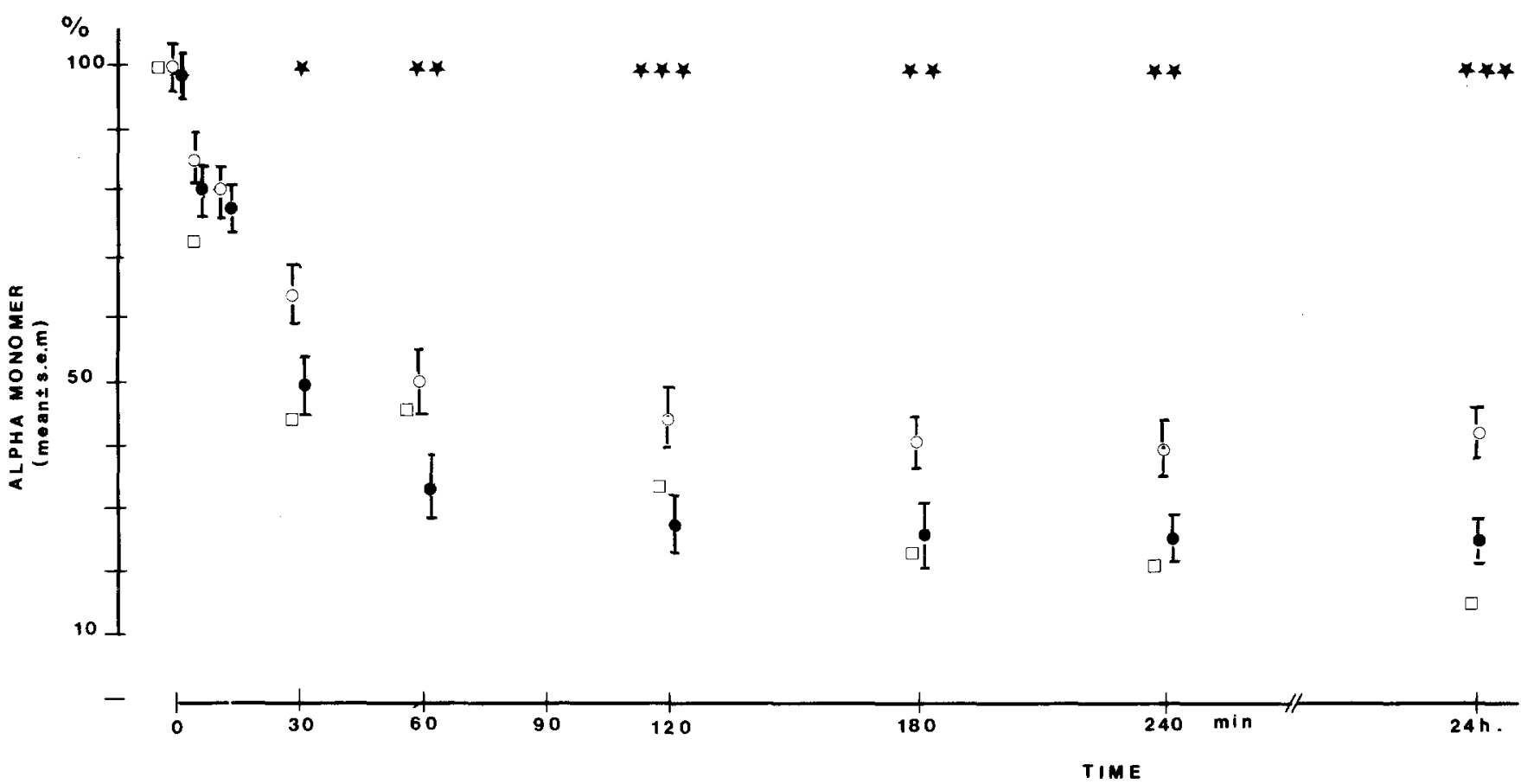

Fig.4. Decrease of alpha monomers in control subjects $(C, n=10)$ and diabetic patients $(D, n=8)$. $\bigcirc$ diabetic subjects; control subjects; $\square$ well controlled diabetic patient. * $p<0.01, * * p<0.005, * * * p<0.001$

\section{Crosslinking}

SDS-PAG electrophoresis of reduced fibrin monomers showed three distinct bands (Fig. 2 and 3, lanes 1 and 2). When thrombin and $\mathrm{CaCl}_{2}$ were added to plasma polymerisation subsequent crosslinking occurred. In Figure 2 and 3 lanes 3-16 the course of the crosslinking process during $24 \mathrm{~h}$ is shown. Within $3 \mathrm{~min}$ the gamma band disappeared, while the gamma-gamma dimer was formed. During the following hours, alpha chain polymerisation occurs, as seen from a decrease in alpha monomer and an increase first in the intermediate alpha-polymers and later in the high molecular weight alpha-n polymer.

In gamma-chain crosslinking, no difference could be shown between the two groups. Alpha-chain crosslinking, however, seemed to be different. In the SDSPAGE slabs, it can be seen that a substantial amount of alpha chain remained unchanged, more intermediate alpha-polymers occurred, and less high molecular weight alpha- $n$ polymers were formed in the diabetic patients compared to the control subjects.

In the 10 control subjects and in the 9 diabetic patients ( 8 poorly controlled, 1 well controlled), the remaining amount of alpha monomer was calculated as follows: the gels were scanned by densitometer. Areas under scan of the alpha chains were compared with the sums of the areas under scan of the $\beta, \gamma, \gamma$-dimer, $\alpha_{\text {int }}$ and $\alpha_{\mathrm{n}}$ chains to give an $\alpha$ ratio. At point $0, \alpha$ chain area was postulated $100 \%$. From Figure 4, it can be seen that the decrease in alpha monomer was significantly slower $(p<0.01)$ in the diabetic patients.
The values for the well controlled diabetic patient were well within the normal range.

FXIII in the diabetic patients as well as in the control subjects, estimated by the clotting test, was $80-110 \%$ (mean 98\%). When estimated by the FXIII ${ }^{\mathrm{a}}$ inhibition test FXIII of 6 control subjects was $107.5 \pm 8.3 \%$ and in 6 diabetic patients $104.2 \pm 9.5 \%$ (mean \pm SEM, NS). There was a negative correlation between the degree of glycation of fibrinogen and the disappearance of the alpha monomer $(r=-0.88$, $p<0.005$, orthogonal regression analysis) (Fig.5). No correlation could be found between age and alpha monomer decrease.

\section{Clotting rate of fibrinogen using thrombin and reptilase}

As is shown in Table 2, no difference in reaction with reptilase could be found between control subjects and diabetic patients. The reaction with thrombin, however, was slower in the diabetic patients compared to the control subjects. There is a slight negative correlation between the $\mathrm{HbA}_{1}$ and the reaction-rate in the thrombin experiment. ( $\tau=0.49, p<0.02$, Kendall rank test). No correlation was found between age and reaction rate.

\section{Clotlysis by plasmin}

In Figure 6, lysis of fibrin clots shows that clots of poorly controlled diabetic patients $(n=5)$ are more susceptible to plasmin clotlysis than clots of control subjects $(n=9)$. Two well controlled patients showed 


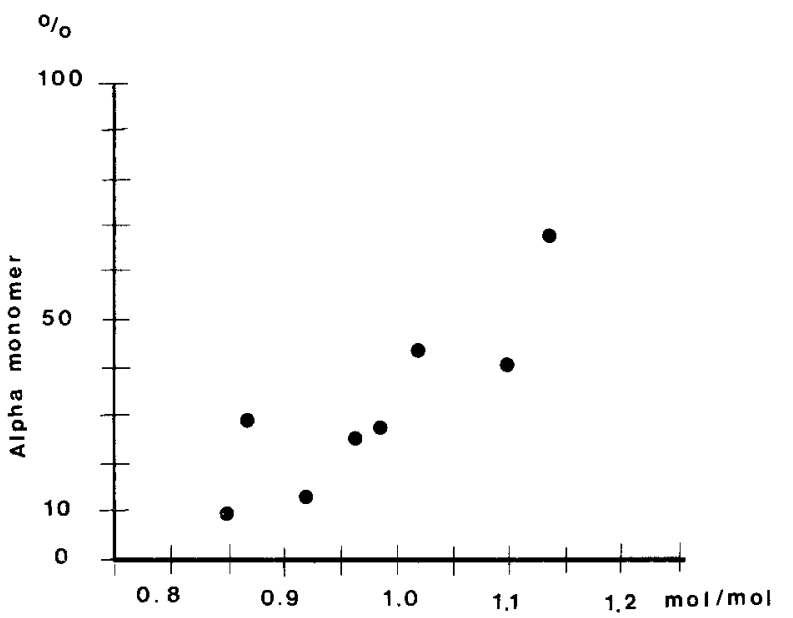

Fig. 5. Correlation between degree of glycation of fibrinogen (mol glucose $/ \mathrm{mol}$ fibrinogen) and alpha monomer disappearance. $(r=0.86, p<0.005)$

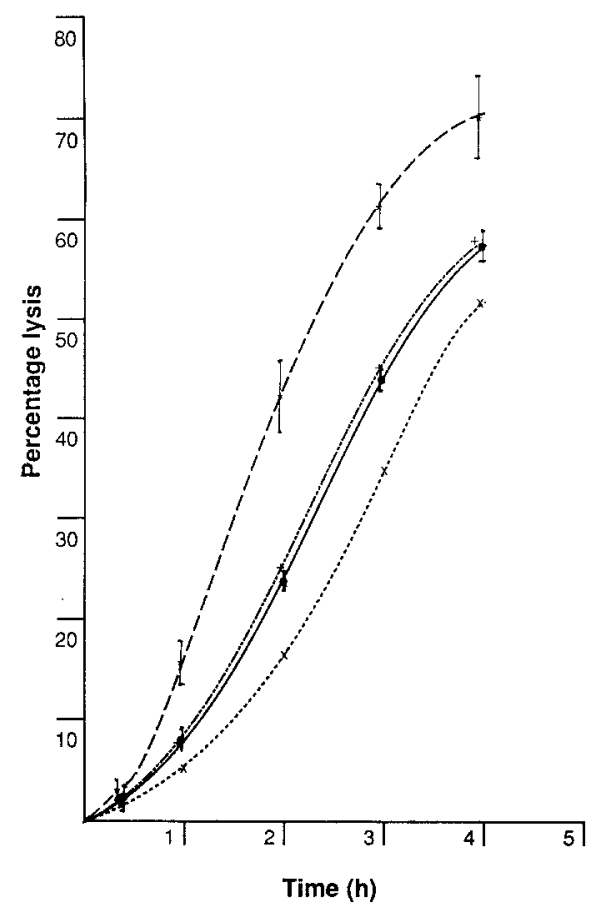

Fig. 6. Lysis rate of fibrin clots from $*^{-----*}$ diabetic subjects $n=5,1.31 \pm 0.06 \mathrm{~mol}$ glucose $/ \mathrm{mol}$ fibrinogen; $\times----\times$ diabetic patient, $1.08 \mathrm{~mol}$ glucose $/ \mathrm{mol}$ fibrinogen; +.....+ diabetic patient, $1.11 \mathrm{~mol}$ glucose/mol fibrinogen; - control subjects $n=9$, $1.03 \pm 0.03 \mathrm{~mol}$ glucose $/ \mathrm{mol}$ fibrinogen. (mean $\pm \mathrm{SEM}$ ). Difference between diabetic patients and control subjects: at $30 \mathrm{~min}$ : NS; at $1 \mathrm{~h}: p<0.01$; at $2 \mathrm{~h}, 3 \mathrm{~h}, 4 \mathrm{~h}: p<0.005$

Table 2. Reaction rate, expressed as maximal increase in absorbance at $350 \mathrm{~nm}\left(\Delta \mathrm{A}_{\max }, 350 \mathrm{~nm} / \mathrm{min}\right)$ after addition of $1 \mathrm{U} / \mathrm{g}$ fibrinogen of thrombin or reptilase to plasma of 12 control subjects (C) and 16 diabetic patients (D)

\begin{tabular}{llll}
\hline & $\Delta \mathrm{A} \max , 350 \mathrm{~nm} / \mathrm{min} .($ mean $\pm \mathrm{SEM})$ & $p$ \\
\cline { 2 - 3 } & $\begin{array}{lll}\text { Control subjects } \\
n=12\end{array}$ & $\begin{array}{l}\text { Diabetic patients } \\
n=16\end{array}$ & \\
\hline Reptilase & $507 \pm 22$ & $503 \pm 20$ & NS \\
Thrombin & $784 \pm 51$ & $580 \pm 21$ & $<0.001$ \\
\hline
\end{tabular}

values comparable to the control group. In the 5 poorly controlled diabetic subjects, $1.31 \pm 0.06 \mathrm{~mol}$ glucose was bound per mol fibrinogen versus $1.11 \mathrm{~mol} / \mathrm{mol}$ and $1.08 \mathrm{~mol} / \mathrm{mol}$ for the 2 well controlled patients. (Nine control subjects: $1.05 \pm 0.02 \mathrm{~mol}$ glucose $/ \mathrm{mol}$ fibrinogen, $p<0.01$ in comparison to the poorly controlled diabetic patients, mean \pm SEM). Correlation between mol glucose bound per mol fibrinogen and fibrin lysis was $\tau=1.0, p<0.005$ (Kendall rank test).

\section{Discussion}

When thrombin is added to fibrinogen, fibrinopeptides $\mathrm{A}$ and $\mathrm{B}$ are released and fibrin monomers are formed. Polymerisation then starts with an end to end alignment of the fibrin monomers, leading to a growing protofibril. Mainly electrostatic forces are involved. When $\mathrm{Ca}$ ions and thrombin activated clotting factor XIII are present, covalent end to side isopeptide bonds are formed between adjacent $\varepsilon$-aminogroups of lysine and $\gamma$-carboxyamidogroups of glutamine. This process leads to a stable crosslinked clot.

Fibrinopeptide release also is catalysed by reptilase, but no activation of clotting factor XIII occurs [20]. The finding that no difference in polymerisation is shown between the diabetic patients and the control subjects, therefore, seems to be consistent with the results of the reptilase experiment. End to end growth of the fibrin monomers was normal as can be seen from the identical lag times in the polymerisation curves. Polymerisation, therefore, does not seem to be inhibited by the increased glycation of the fibrin molecule. These results also suggest that the fpA release does not differ between the two groups. This has to be confirmed by direct measurement of the fpA release after thrombin addition. Lysine molecules are actively involved in the crosslinking process. Gamma chain dimerisation did not seem to be affected by the higher degree of glycation in the diabetic group. Alpha chain crosslinking, however, showed incomplete disappearance of the alpha monomer and a persistent occurrence of intermediate alpha-polymers. The incomplete alpha polymerisation was positively correlated to the degree of glycation of fibrinogen (Fig.5). In accordance with this finding, a positive correlation between the slower thrombin reaction and $\mathrm{HbA}_{1}$ was also observed. These results are compatible with a causal relationship between abnormal clotting behaviour and poor metabolic control.

The finding of normal gamma-chain crosslinking in the presence of decreased alpha crosslinking can be explained by the fact that only one pair of crosslinking sites is present per gamma monomer, versus 6 per alpha monomer. Also, it was suggested by McVerry [9] that in vitro the alpha chain of fibrinogen is glycated to a higher degree than the beta or gamma chains. The diminished crosslinking could not be explained by a low factor XIII concentration in the diabetic patients, as no differences in FXIII concentration are found be- 
tween the two groups, when estimated by two methods. This is in accordance with the findings of Kloczko et al. [21], in diabetic patients without angiopathy. In the lysis experiments purified fibrinogen of diabetic patients and control subjects was clotted by the addition of thrombin, $\mathrm{Ca}^{++}$and a standard amount of FXIII. Control SDS-PAG electrophoresis of the clots after $20 \mathrm{~h}$ showed the same findings of an impaired disappearance of alpha chains and appearance of $\alpha_{\text {int }}$ in the diabetic patients, comparable to Figures 2 and 3 , band $24 \mathrm{~h}$ (results not shown).

Although the diabetic group was significantly older than the control group, no correlation was found between age and abnormal alpha-chain crosslinking. The well controlled patient, aged 83, showed a normal alpha chain crosslinking pattern. We, therefore, suggest that in poorly controlled diabetic patients crosslinking of the alpha chains is impaired.

As a consequence of impaired crosslinking, a higher susceptibility to plasmin degradation could be expected, as has been shown in several studies not concerning diabetic patients $[22,23]$. From Figure 5, it can be seen that there is a higher susceptibility to plasmin degradation in the clots from purified fibrin obtained from poorly controlled diabetic patients. There is a positive relationship between degree of glycosylation and plasmin lysis rate. In these experiments nondiabetic plasminogen was added after removal of the endogenous plasminogen, because of the finding of Geiger et al. [24] who showed an increased glycosylation of plasminogen in poorly controlled diabetic patients, leading to impaired kinetics of plasminogen activation.

In contrast to our findings, Brownlee et al. [25] reported a reduced susceptibility of glycosylated fibrin to plasmin degradation. They, however, used un-physiological, extremely high glucose or glucose-6-phosphate concentrations up to $500 \mathrm{mmol} / \mathrm{l}$ over a three week incubation period. No data on the amount of glucose bound per mol fibrinogen are given in their article.

We, therefore, suggest that in poorly controlled diabetic patients impaired alpha-chain crosslinking of fibrin monomers occurs, leading to a less stabilized clot, which is more susceptible to plasmin degradation.

Acknowledgement. Financial support for this study was given by the Diabetes Fonds Nederland. We thank Ms. Sanderson-Sellmeijer for her technical support.

\section{References}

1. Farquahr A, MacDonald MK, Ireland JT (1972) The role of fibrin-depositions in diabetic glomerulosclerosis: a light electron and immunofluorescence microscopy study. J Clin Pathol 25: 657-661

2. Brownlee M, Vlassara H, Cerami A (1983) Nonenzymatic glycosylation reduces the susceptibility of fibrin to degradation by plasmin. Diabetes 32: 680-684

3. Jones RL, Jovanovic L, Forman S, Peterson ChM (1984) Time course of reversibility of accelerated fibrinogen disappearance in diabetes mellitus: association with intravascular volume shifts. Blood 63: 22-30
4. Tsianos EB, Stathakis NE (1980) Soluble fibrin complexes and fibrinogen heterogeneity in diabetes mellitus. Thromb Haemost 44: $130-134$

5. Gurewich V, Lipinska I, Pulini M, Gordon E, Lipinski B (1977) Fibrinogen, fibrinogen heterogeneity and fibrinolytic activity in diabetes mellitus. Thromb Haemost 38: 103

6. Jones RL, Peterson ChM (1979) Reduced fibrinogen survival in diabetes mellitus. J Clin Invest 63: 485-493

7. DaSilva SR, Shawe JEH, Patel H, Cudworth AG (1979) Plasma fibrinogen in diabetes mellitus. Diabete Metab 5: 201-206

8. Wieland OH (1983) Protein modification by nonenzymatic glycosylation: a possible role in the development of diabetic complications. Mol Cell Endocrinol 29: 125-131

9. McVerry BA, Thorpe S, Joe F, Gaffney P, Huehns ER (1981) Non enzymatic glycosylation of fibrinogen. Haemostasis 10 : 261-270

10. Lütjens A, te Velde AA, v d Veen EA, v d Meer J (1985) Glycosylation of human fibrinogen in vivo. Diabetologia 28: 87-89

11. Lorand L, Ong HH, Lipinski B, Rule HG, Downey J, Jacobsen A (1966) Lysine as amine donor in fibrin crosslinking. Biochem Biophys Res Comm 25: 629-637

12. WHO Study Group Diabetes Mellitus (1985) Technical Report Series 727. World Health Organisation, Geneva, Switzerland

13. Belitser VA, Varetskaja TV, Malneva GV (1968) Fibrinogen-fibrin interaction. Biochim Biophys Acta 154: 367-369

14. Olexa SA, Budzynski AZ (1980) Evidence for four different polymerisation sites involved in human fibrin formation. Proe Natl Acad Sci USA 77: 1374-1378

15. McDonagh J, Messel H, McDonagh RP jr, Murano G, Blomback B (1972) Molecular weight analysis of fibrinogen and fibrin chains by an improved sodium dodecylsulfate gel electrophoresis method. Biochim Biophys Acta 257: 135-142

16. Owren PA, Aas K (1951) The control fo dicoumarol therapy and the quantitative determination of prothrombin and proconvertin. Scand J Clin Lab Invest 3: 201-208

17. Deutsch DG, Mertz ET (1970) Plasminogen. Purification from human plasma by affinity chromatography. Science 170: 1095-1096

18. Strengers Th, Asberg EGMTh (1963) Een screeningtest, gevolgd door een snelle kwantitatieve microbepaling van fibrinogeen in plasma. Ned Tijdschr Geneeskd 107: 2044-2045

19. Kendall MG (1970) Rank correlation methods, 4th edn. Griffin, London

20. Bell WR (1982) Defibrinating enzymes. In: Colman RW, Hirsch J, Marder VJ, Salzman EW (eds) Hemostasis and thrombosis. Lippincott, Philadelphia, pp 1013-1027

21. Kloczko J, Wojtukiewicz M, Dielawiec M, Larzycka B, Kinalska $J$ (1986) Plasma factor XIII and some other haemostasis parameters in patients with diabetic angiopathy. Acta Haematol (Basel) 76: $81-85$

22. Kirkpatrick JP, McIntire LV, Moake JL (1978) Streptokinase-induced degradation of crosslinks and uncrosslinked clots. Thromb Res 13: 569-575

23. Francis CW, Marder VJ, Barlow G (1980) Plasmic degradation of corsslinked fibrin. J Clin Invest 66: 1033-1043

24. Geiger M, Binder BR (1986) Non enzymatic glucosylation as a contributing factor to defective fibrinolysis in diabetes mellitus. Haemostasis 16: 439-446

25. Brownlee M, Vlassara H, Cerami A (1983) Non enzymatic glycosylation reduces the susceptibility of fibrin to degradation by plasmin. Diabetes 32: 680-684

Received: 10 March 1988

and in revised form: 5 October 1988

Dr. A. Lütjens

Andreas Ziekenhuis

Th. de Bockstraat 8

NL-1058 NR Amsterdam

The Netherlands 